\title{
Constitutive Modelling of Laser Based Powder Bed Fusion Melted Inconel 718 Superalloy over a Wide Range of Strain Rates
}

\author{
Laura DELCUSE ${ }^{\mathrm{a}}$, Slim BAHI ${ }^{\mathrm{a}}$, Urvashi GUNPUTH ${ }^{\mathrm{b}}$, Paul WOOD ${ }^{\mathrm{b}}$ and Alexis \\ RUSINEK $^{\mathrm{a}}$ \\ ${ }^{a}$ Laboratory of Microstructure Studies and Mechanics of Materials, UMR-CNRS 7239, \\ 7 rue Félix Savart, 57000 Metz, France \\ ${ }^{\mathrm{b}}$ Institute of Innovation in Sustainable Engineering (IISE), University of Derby, Quaker \\ Way, Derby, United Kingdom
}

\begin{abstract}
The aim of this paper is to determine the material parameters of the Inconel 718 manufactured by Laser Powder Bed Fusion, using the Johnson-Cook model. Different compression tests in quasi-static and dynamic domains were performed under various strain rates, in range of $10^{-3} \mathrm{~s}^{-1}$ to $2500 \mathrm{~s}^{-1}$ at the room temperature. The difference between the two building directions $\mathrm{XY}$ and ZX, horizontal and vertical position from the substrate, was investigated to highlight the influence of the process parameter on the bulk material behavior. Finally, the identified parameters were implemented into a numerical model, describing the behavior of auxetic structure under compression test, and validated using experimental data.
\end{abstract}

Keywords. Powder Bed Fusion, Inconel 718, Constitutive model

\section{Introduction}

Nickel-based superalloys have been widely used in industrial application with regards to its high strength, good oxidation resistance and so on [1]. The behaviour of such alloys has been often characterized in order to provide good predictability for computational modelling [1]. However, those materials are considered as difficult to machining due to its high hardness.

Since few decades, the Additive Manufacturing was extensively studied for its novelty and its convenience to print complex structure. Furthermore, some materials, like Inconel 718, provides high mechanical properties by additive manufacturing process as compared to conventional methods, as shown Trosch et al [2]. The process used in this paper is the Laser Powder Bed Fusion (L-PBF) which is a layer by layer additive manufacturing. The mechanical properties of the printed material is dependent of the process parameters such as the laser power, the scanning speed and the building direction $[3],[4]$.

In this work, Inconel 718 printed by Additive Manufacturing, more precisely by Laser Powder Bed Fusion (L-PBF), was studied in order to determine a constitutive model based on Johnson-Cook. Two building direction, XY (horizontal) and ZX 
(vertical) was investigated (Figure 1). The found model was validated by numerical modelling on a printed auxetic structure and compared to experimental data.

\section{Experimental procedure}

\subsection{Material characteristics and process parameters}

In this paper, Inconel 718 was printed by Additive Manufacturing process, more precisely by Laser Powder Bed Fusion (L-PBF) using a Renishaw AM250, with a 200W pulse wave fibre laser and $70 \mu \mathrm{m}$ focal diameter, a build volume of 250x250x300 mm and a layer deposition ranging from 20 to $100 \mu \mathrm{m}$.

Spherical powder of Inconel 718 was used, with particle size between 15 and $45 \mu \mathrm{m}$, with a chemical composition of Ni-55Cr-17Fe-18Nb-5Mo-2.8Ti-1Al (\%wt).

The printing parameters of the samples was chosen following the previous study of Delcuse et al. [5] and set with a laser power of $175 \mathrm{~W}$, time exposure of $164 \mu$ s and a layer thickness of $30 \mu \mathrm{m}$.

After the AM process, a heat treatment was applied in order to stress relieve the part pieces. Then, the built samples were removed from the substrate with a wire cut Electrical Discharge Machining process (AgieCharmilles Cut E 350).

For this study, rod bars with dimension of $8 \mathrm{~mm}$ in diameter and height of $40 \mathrm{~mm}$ were printed in two building directions, ZX (vertical) and XY (horizontal), as displayed on the Figure 1. Then, each bar was machining in order to have a final diameter of $6 \mathrm{~mm}$, and cylindrical specimen were cut in the rod bar to provide specimen with a height of $3 \mathrm{~mm}$ for dynamic compression and $6 \mathrm{~mm}$ for quasi-static compression.

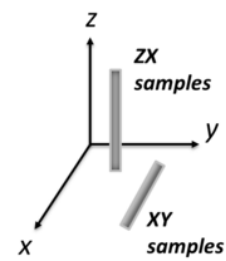

Figure 1. Building direction of the ZX and XY building direction

\subsection{Quasi-static compression test}

The quasi-static compression test was performed using a ZWICK compression test machine with a maximum force cell of $100 \mathrm{kN}$. The deformation was carried out at different strain rate of $10^{-3} \mathrm{~s}^{-1}, 10^{-2} \mathrm{~s}^{-1}$ and $10^{-1} \mathrm{~s}^{-1}$ at the room temperature. An extensometer was used to record the real displacement of the sample during the compression, placed on the jaws. Each condition was realized four times in order to provide a good repeatability.

\subsection{Dynamic compression test}

The dynamic compression behavior of the printed Inconel 718 was characterized using a Split Hopkinson Pressure Bar (SHPB) at the room temperature, in a range from 1000 
$\mathrm{s}^{-1}$ to $2500 \mathrm{~s}^{-1}$, with 3 samples per condition. The results from the SHPB devices were analyzed in the WASP (Waves Analysis and Study Program). For each test, the dimension of the samples and the velocity was necessary to sort the True Strain - Stress curves.

\subsection{Auxetic structure}

In order to validate the constitutive model, a dynamic compression on SHPB at room temperature was performed on an auxetic structure, manufacturing with the same process parameters as the previous samples. With regards to the previous paper [5], the auxetic structure built in XY exhibit the best mechanical properties as well as accuracy in dimension, hence the auxetic structure were only printed in that direction for the SHPB test. The dimension of the auxetic was designed as function of the diameter of the bar of the SHPB to allow a correct position of the structure in the system, which leds to a $3 \times 3$ cells and a solid of $10 \times 10.514 \times 10.76 \mathrm{~mm}$.

A dynamic compression test on this auxetic structure was performed at a strain rate about $600 \mathrm{~s}^{-1}$, at the room temperature. The test was recorded by a high-speed camera in order to provide the deformation during the compression of the specimen.

\subsection{Numerical modelling and boundary conditions}

A finite element model was established to validate the constitutive model by modeling the compressive behavior of the auxetic structure using the commercial software Abaqus ${ }^{\circledR}$. The two bars of the SHPB system was modeled as a rigid plate with respectively on reference point which was used to applied the velocity and the encastred constraint. The auxetic structure was meshed with C3D10M element, which is a 10-node modified quadratic tetrahedron, for a total of 86482 elements. General contact was used to define the surface contact between the plate and the auxetic, as well as the self-contact of the structure. The coefficient of friction was set to 0.05 .

As concerned the material behavior, a density $\rho$ of $8.19 \mathrm{~g} . \mathrm{cm}^{-3}$, a Young modulus E of $180 \mathrm{GPa}$ and a Poisson's ratio $v$ of 0.29 was set up. A Johnson-cook behavior was adopted with the constant parameters found with the experimental part for the XY building direction, and explained in the next section.

The previous experimental data was compared to the simulation, in term of stressstrain curves.

\section{Results and discussion}

\subsection{Experimental results}

The true stress - true strain curves for quasi-static and dynamic compression were plotted for the printed Inconel 718 for the both building direction $\mathrm{ZX}$ and $\mathrm{XY}$ at the room temperature, and are represented in Figure 2. 
It can be noticed that the XY building direction (horizontal) had better mechanical properties in term of yield stress and stress level as compared to the ZX building direction (vertical), in both quasi-static and dynamic conditions. In addition, the flow stress was not very sensitive to the strain rates, as shown the Figure 2.

(a)

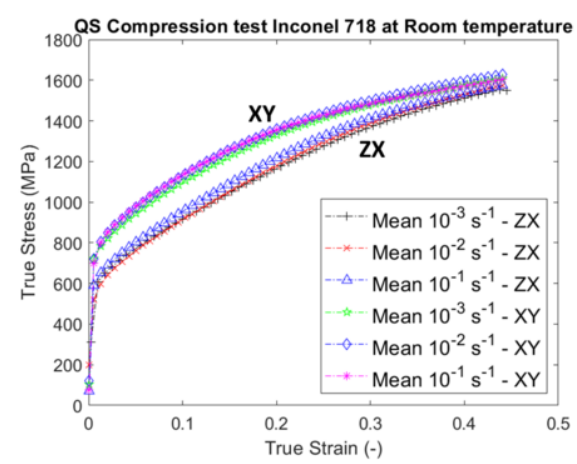

(b)

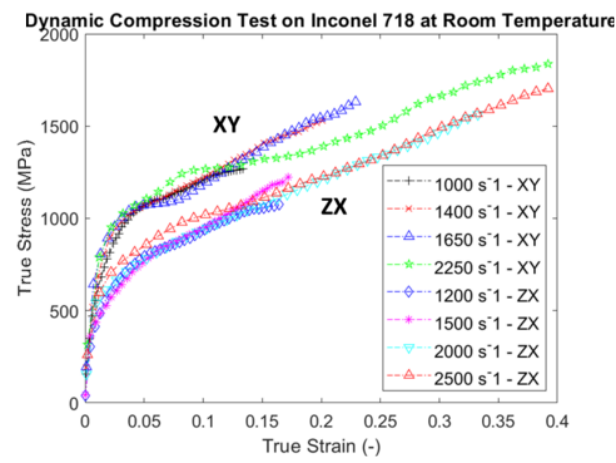

Figure 2. True stress - True Strain curves of printed Inconel 718 deformed in (a) quasi-static and (b) dynamic condition at the room temperature

\subsection{Determination of material constant}

In this work, the Johnson-cook model was chosen to describe the dynamic behavior of the Inconel 718. With regards to the high accuracy and mathematical simplicity, this model was widely used and was suitable for high strain rates. The Johnson-cook model is given by the following Eq. (1):

$$
\sigma=\left(A+B \varepsilon^{n}\right)\left(1+C \ln \left(\frac{\dot{\varepsilon}}{\dot{\varepsilon}_{0}}\right)\right)\left(1-\frac{T-T_{r}}{T_{m}-T_{r}}\right)^{m}
$$

Where $\sigma$ is the flow stress and $\varepsilon$ the plastic strain. $\dot{\varepsilon}$ is the plastic rate while $\dot{\varepsilon}_{0}$ is the reference strain rates, fixed to $10^{-3} \mathrm{~s}^{-1}$. A, B, C, n and $\mathrm{m}$ are considered to be material constant identified experimentally. The reference temperature $\mathrm{Tr}$ was set to the room temperature, $20^{\circ} \mathrm{C}$.

With regards to the thermo-mechanical properties of the Inconel 718, the thermal softening effect was not studied in this work. Indeed, the thermal softening of the Inconel 718 starts at $700^{\circ} \mathrm{C}[6]$, hence we assume that the parameter $\mathrm{m}$ can be negligible for our study. Finally, the material constant to determine are A, B, C and n, for both specimens printed in $\mathrm{ZX}$ and $\mathrm{XY}$ building direction.

Firstly, the values A, B and $n$ were obtained by a non-linear curve fitting from the quasi-static experimental data at reference strain and reference temperature.

Then, the constant $\mathrm{C}$ was calculated with the SHPB test at different strain rates, for $\varepsilon=0.04$ in order to determine the strain rate sensitivity. By plotting the formula $\sigma /\left(A+B \varepsilon^{n}\right)$ 

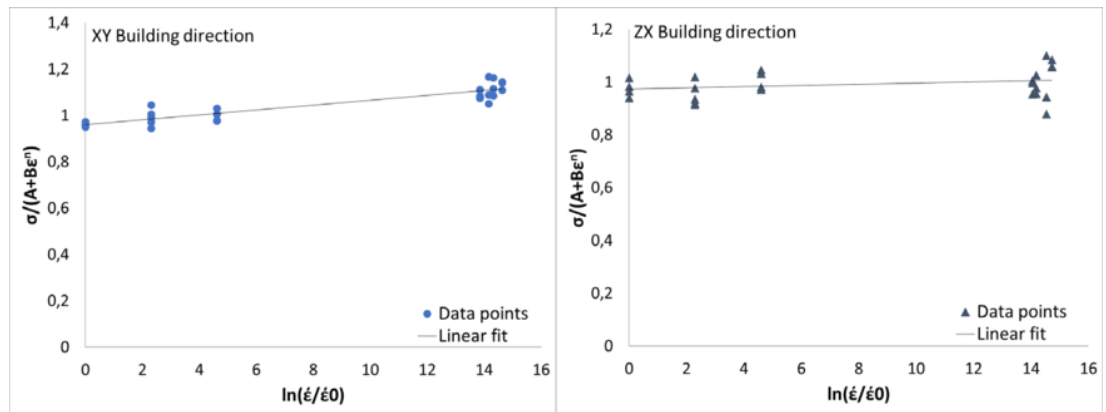

Figure 3. Plot of $\sigma /\left(\mathrm{A}+\mathrm{B} \varepsilon^{\mathrm{n}}\right)$ against $\ln \left(\frac{\dot{\varepsilon}}{\dot{\varepsilon}_{0}}\right)$ at reference temperature

against $\ln \left(\frac{\dot{\varepsilon}}{\dot{\varepsilon}_{0}}\right)$ as displayed on the Figure 3, the constant $\mathrm{C}$ was obtained by the slope of the linear fit. The material constants of Inconel 718 printed in ZX and XY building direction were summarized in the Table 1.

The results from the determination of the constant material demonstrated a slight difference between the building direction $\mathrm{XY}$ and $\mathrm{ZX}$, which could be associated to the microstructure, as shown Deng and al [3].

Table 1. Johnson-Cook Material constant of the Inconel 718 printed in $\mathrm{ZX}$ and XY building direction

\begin{tabular}{lrrrl}
\hline J-C material constant & A & B & \multicolumn{1}{c}{ C } & \multicolumn{1}{c}{ n } \\
\hline ZX building direction & 520 & 1826 & 0.0023 & 0.64 \\
XY building direction & 720 & 1777 & 0.0106 & 0.6535 \\
\hline
\end{tabular}

\subsection{Validation of constitutive model}

Dynamic compression test was carried out on auxetic structure, with a strain rate of approximatively $600 \mathrm{~s}^{-1}$. Then, in order to validate the Johnson-Cook model find by the experimental part, numerical modeling was running on the same auxetic structure, and compared to the previous experimental test of dynamic compression. The true stress true strain curves was shown on Figure 4.

The numerical model of the dynamic compression of an auxetic structure printed in Inconel 718 by L-PBF is in agreement with the experimental data. The both flow stress as displayed on Figure 4 are quite similar. Finally, the as-determined Johnson-Cook model is validated by this simulation.

\section{Conclusion}

In this work, Inconel 718 manufactured by L-PBF with special process parameters was characterized for both building direction ZX (vertical) and XY (horizontal), by quasistatic and dynamic compression test. The constant parameters of the Johnson-cook model were determined from experimental data and validated with a numerical modelling of a compressed auxetic structure. 


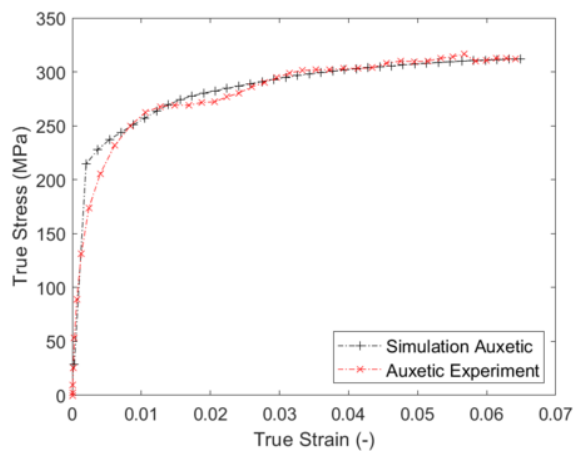

Figure 4. True Stress - True strain curves of experiment and numerical modelling on dynamic compression of auxetic structure

The experimental test at high strain rates had shown the slight sensitivity to the strain rates for the two building direction. In addition, XY building direction exhibit a higher stress level compared to the ZX. Due to this discrepancy, the Johnson-cook model parameters are different in order to provide the correct flow stress with regard to the experimental part.

\section{Acknowledgements}

This research was supported by the LEM3 of the University of Lorraine at Metz and the IISE of the University of Derby, who provided all the specimen for the tests. The authors thank M. Richard BERNIER for his precious help during the experimental test.

\section{References}

[1] X. Wang, C. Huang, B. Zou, H. Liu, H. Zhu, and J. Wang, Dynamic behavior and a modified JohnsonCook constitutive model of Inconel 718 at high strain rate and elevated temperature, Materials Science and Engineering: A, $\mathbf{5 8 0}$ (2013), 385-390.

[2] T. Trosch, J. Strößner, R. Völkl, and U. Glatzel, Microstructure and mechanical properties of selective laser melted Inconel 718 compared to forging and casting, Materials Letters, 164 (2016), 428-431.

[3] D. Deng, R. L. Peng, H. Brodin, and J. Moverare, Microstructure and mechanical properties of Inconel 718 produced by selective laser melting: Sample orientation dependence and effects of post heat treatments, Materials Science and Engineering: A, 713 (2018), 294-306.

[4] J. H. Yi et al., Effect of laser energy density on the microstructure, mechanical properties, and deformation of Inconel 718 samples fabricated by selective laser melting, Journal of Alloys and Compounds, 786 (2019), 481-488.

[5] L. Delcuse, S. Bahi, U. Gunputh, A. Rusinek, P. Wood, and M. H. Miguelez, 'Effect of powder bed fusion laser melting process parameters, build orientation and strut thickness on porosity, accuracy and tensile properties of an auxetic structure in IN718 alloy, Additive Manufacturing, 36 (2020), 101339.

[6] A. Iturbe et al., Mechanical characterization and modelling of Inconel 718 material behavior for machining process assessment, Materials Science and Engineering: A, 682 (2017), 441-453. 